\title{
Assessment of Middle Aged Teacher's Knowledge about Hormone Replacement Therapy
}

\author{
${ }^{1}$ Hanan Ali Kadhom, ${ }^{2}$ Ezedeen Fakhreldeen Baha`aldeen \\ ${ }^{1}$ (Maternal and newborn health, medical city hospital, Iraq) \\ ${ }^{2}$ (Maternal and newborn health, College of Nursing, University of Baghdad, Iraq)
}

\begin{abstract}
:
Background: Hormone Replacement Therapy (HRT) is the term used for the administration of estrogen, or estrogen with progestin, to women who have attained menopause. Estrogen is most commonly given with progestin to women who still have a uterus, Hormone replacement therapy (HRT) is an used for treating menopausal symptoms such as vasomotor symptoms, sleep disturbances, mood change, depression, urinary tract infection, vaginal atrophy and increased incidence for osteoporosis, cardiovascular diseases and loss of cognitive function.(1)
\end{abstract}

Objectives: This study was conducted to assess Teachers' knowledge about hormone replacement therapy. Material and Methods: across sectional descriptive and analytical study was carried out to assess middle aged teacher's knowledge about hormone replacement therapy in Baghdad city. The study was carried out at education directorates of Primary and secondary Schools in $1^{\text {st }}$ and $2^{\text {nd }} A L$-Karkh, and in $2^{\text {nd }}$ and $3^{\text {rd }}$ Rusafa in Baghdad City. The sample consists of 400 teachers aged (35-60) years. To achieve objectives of the present study a questionnaire format was used for data collection which consisted of (2) parts: first part is concerned with teachers' socio-demographic characteristics, second part is concerned with knowledge regarding hormone replacement therapy.

The results: of the study represent that the mean of middle aged teachers was (44 $\pm 7 S D)$, the majority of sample $(80.5 \%)$ were married, and $(74.8 \%)$ were college graduate, the mean score of knowledge show poor level of knowledge $(30.1 \pm 22.3 S D)$ regarding hormone replacement therapy. Level of knowledge was not associated with level of education.

Conclusion: The study indicated that there is poor knowledge about HRT among the participants. Level of knowledge was not associated with level of education.

Keywords: Hormone replacement therapy, Knowledge, Middle age, Teachers

\section{Introduction}

Hormone replacement therapy (HRT) still the first line of treatment and the most efficient for the symptoms of menopause, currently used for three key indicators are: the prevention of osteoporosis and prevention of coronary artery (CAD) disease and treatment of menopausal symptoms (2)

After ten years of randomized treatment, women receiving hormone replacement therapy early next menopause had a significantly reduced risk of mortality, heart failure, or myocardial infarction, without any visible increase in risk of cancer, venous thromboembolism, or Stroke. (3)

Hormone replacement therapy (HRT) can be taken orally and non-orally. Due to the provision of similar doses, all forms of HRT can evenly reduce menopausal symptoms and prevent loss of bone and osteoporosis. (4)

Observational studies carried out through the 1990s; suggest that HT in menopausal women is effective in relieving symptoms, and in reducing public health problems like cardiovascular diseases and osteoporosis. (5)

In 2003, the Million Women Study detect an increase in breast cancer incidence associated with HT. (6)

For more than 50 million American women, and millions of women in other countries who more than 50 years age , the decision whether or not to use estrogen replacement therapy (ERT) for chronic disease prevention is predominating a difficult one. Established benefits of treatment for symptoms of menopausa and prevention of osteoporosis must be scaled against documented risks of treatment, including venous thromboembolic events (VTE), gallbladder disease, and is probable to increase the risk of breast cancer. (7)

The effect of hormone replacement therapy on cardiovascular disease (CVD) is of big importance to public health, because CVD is the leading cause of death and a main contributor to disability in women. (8)

Women are misinformed regarding menopause status and its management. Increase knowledge about menopause and hormone replacement therapy is important. Menopause is stressful event in women`s life that need attention to help them maintain their life. The women need comprehensive information about hormone 
therapy, benefits and risks, these information increase women background about this period of life and its management. When children leave home and women find their selves alone with increased incidence of psychosomatic symptoms. For that, the idea of managing menopause by hormone Replacement therapy (HRT) is becoming preferable to improvement the recent complaint of menopause and to prevent its medical sequel such as osteoporosis and ischemic heart disease. This study attempts to summarize issues related to hormone replacement therapy and the amount of information among school teachers as community sample.

\section{Material and Methods}

A cross sectional descriptive and analytical study was carried out to assess middle aged teacher`s knowledge about menopause in Baghdad city, The sample consists of 400 teachers who teaches in primary and secondary schools in Baghdad city, The data collection were obtained through writing questionnaire. The data collection process has been performed from $27^{\text {th }}$ February 2016 until $30^{\text {th }}$ March 2016. An approximately (3045) minutes spent with each responder to complete filling of the questionnaire, The instrument is a Data sheet which were consists of as following parts: Part one: Socio-demographic data: This part was designed to include items that represent the information related to age in years, marital status, educational level, absent of menstrual cycle for more than one year and using of hormone replacement therapy, Part Two concerning knowledge: This part concerning the knowledge about hormone replacement therapy, the items were scaled with third likert scale rating as: (1) disagree, (2) neutral and (3) agree, Likert scale is normally preferred to have a detail view of belief of respondents or their perceptions about the point of discussion. Wrong questions was included in five items as the followings: Item (2.10) which refer to : HRT is available as injection, (2.12) which refer to : oestrogen reduces the absorption of calcium, (2.14) which refer to: breast pain appears after a long period of receiving HRT, (2.20) which refer to ; HRT contraindication in cases with urinary tract infection, (2.21) which refer to: HRT contraindication in cases with bone pain. Data analysis of study sample was done by using the SPSS (Statistical Package for Social Sciences) (version 18), using percentage \%, T-test and ANOVA Test.

\section{Result}

Table (1): Frequency distribution of study sample by sociodemographic variable $(\mathrm{N}=400)$ :

\begin{tabular}{|c|c|c|}
\hline Demographic characteristics & Frequency & Percent $\%$ \\
\hline \multicolumn{3}{|l|}{ Age group (years) } \\
\hline$<40$ & 127 & 31.8 \\
\hline $40-49$ & 171 & 42.8 \\
\hline $50+$ & 102 & 25.5 \\
\hline \multicolumn{3}{|c|}{ Mean age $44 \pm 7$ SD by Rang (35-60)years } \\
\hline \multicolumn{3}{|l|}{ Marital status } \\
\hline Single & & 14.3 \\
\hline Married & 322 & 80.5 \\
\hline Divorced & 9 & 2.3 \\
\hline Widow & 12 & 3.0 \\
\hline \multicolumn{3}{|l|}{ Educational level } \\
\hline Institute & 74 & 18.5 \\
\hline College graduates & 299 & 74.8 \\
\hline Higher education & 27 & 6.8 \\
\hline \multicolumn{3}{|c|}{ Absence of Menstrual cycle for more than one year(menopause } \\
\hline Yes & 98 & 24.6 \\
\hline No & 302 & 75.5 \\
\hline \multicolumn{3}{|l|}{ Using HRT } \\
\hline Yes & 26 & 6.5 \\
\hline No & 374 & 93.5 \\
\hline
\end{tabular}

Table 1: Shows the highest percentage 171(42.8\%) of study sample was at age (40-49) years, while the lowest percentage $102(25.5 \%)$ at age group (50+), the mean of middle aged teachers was (44 $\pm 7 \mathrm{SD}), 322$ (80.5\%) of study sample were married, $299(74.8 \%)$ were College graduates, $302(75.5 \%)$ were not absent menstrual cycle,. $374(93.5 \%)$ not use HRT,

Table (2) Distribution of teacher`s knowledge regarding HRT variables

\begin{tabular}{|c|c|c|c|}
\hline & Correctly identified $(n=400)$ & $\mathrm{N}$ & $\%$ \\
\hline \multicolumn{4}{|c|}{ Hormone replacement therapy (HRT) } \\
\hline 2.1 & $\begin{array}{l}\text { Hormone Replacement Therapy (HRT) is considered the optimal treatment for menopausal } \\
\text { symptoms (Correctly agreed with) }\end{array}$ & 170 & 42.5 \\
\hline 2.2 & taking HRT without medical advice may cause endometrial cancer (Correctly agreed with) & 172 & 43.0 \\
\hline 2.3 & women need HRT after hysterectomy (Correctly agreed with) & 166 & 41.5 \\
\hline 2.4 & HRT is given to improve aesthetics for women (Correctly agreed with) & 148 & 37.0 \\
\hline 2.5 & $\begin{array}{l}\text { HRT is prescribed in small quantities to balance the natural physiology of the body } \\
\text { (Correctly agreed with) }\end{array}$ & 161 & 40.3 \\
\hline
\end{tabular}




\begin{tabular}{|c|c|c|c|}
\hline 2.6 & response to HRT differs from one woman to another (Correctly agreed with) & 215 & 53.8 \\
\hline 2.7 & The HRT is prescribed in for systemic use or locally (intra-vaginal) (Correctly agreed with) & 135 & 33.8 \\
\hline 2.8 & HRT is available as tablets (Correctly agreed with) & 139 & 34.8 \\
\hline 2.9 & HRT is available as ointment (Correctly agreed with) & 109 & 27.3 \\
\hline 2.10 & HRT is available as injection (Correctly disagreed with) & 65 & 16.3 \\
\hline 2.11 & HRT is available as skin patch (Correctly agreed with) & 116 & 29.0 \\
\hline 2.12 & oestrogen reduces the absorption of calcium (Correctly disagreed with) & 41 & 10.3 \\
\hline 2.13 & $\begin{array}{l}\text { Preferably A periodic check for the breast and level of blood lipids and BMD before starting } \\
\text { treatment(Correctly agreed with) }\end{array}$ & 174 & 43.5 \\
\hline 2.14 & breast pain appears after a long period of receiving HRT (Correctly disagreed with) & 36 & 9.0 \\
\hline 2.15 & HRT reduces breast cancer (Correctly agreed with) & 124 & 31.0 \\
\hline 2.16 & HRT reduce menopausal symptoms and prevent CVD (Correctly agreed with) & 130 & 32.5 \\
\hline 2.17 & HRT is contraindicated in cases with-breast and endometrial cancer (Correctly agreed with) & 134 & 33.5 \\
\hline 2.18 & HRT is contraindicated in cases with-liver disease (Correctly agreed with) & 127 & 31.8 \\
\hline 2.19 & HRT is contraindicated in cases with-hypertension (Correctly agreed with) & 132 & 33.0 \\
\hline 2.20 & HRT is contraindicated in cases with-UTI (Correctly disagreed with) & 45 & 11.3 \\
\hline 2.21 & HRT is contraindicated in cases with-bone pain (Correctly disagreed with) & 39 & 9.8 \\
\hline
\end{tabular}

Table 2 shows the highest percentages $(53.8 \%)$ of study sample correctly answer with agree regarding item(6.6) which refer to response to HRT differs from one woman to another, while the lower percentages $(9.0 \%)$ regarding item $(6.14)$ which refer to breast pain appears after a long period of receiving HRT were the study sample answer correctly disagree with.

Table (3): knowledge score regarding Hormone Replacement Therapy

\begin{tabular}{|l|l|l|l|l|l|}
\hline Knowledge Score & Range & Mean & SD & SE & N \\
\hline $\begin{array}{l}\text { Knowledge score-hormone } \\
\text { replacement therapy (HRT) }\end{array}$ & $(0$ to 80$)$ & 30.1 & 22.3 & 1.12 & 400 \\
\hline
\end{tabular}

The table (3) shows means score of knowledge (30.1 $\pm 22.3 \mathrm{SD}$ ) had low level of knowledge regarding hormone replacement therapy

Table (4): Relationship between Educational Level and Knowledge Score Regarding HRT

\begin{tabular}{|l|l|l|l|l|l|}
\hline \multirow{2}{*}{$\begin{array}{l}\text { Knowledge score-hormone } \\
\text { replacement therapy (HRT) }\end{array}$} & Educational level & P & Sig \\
\cline { 2 - 4 } & Institute & College graduates & Higher education & & \\
\hline Range & & & & 0.08 & NS \\
\hline Mean & $(0$ to 80$)$ & $(0$ to 75$)$ & & \\
\hline SD & 26.2 & 30.6 & 35 & \\
\hline SE & 22.3 & 22.4 & 20.6 & \\
\hline N & 2.59 & 1.3 & 3.96 & \\
\hline
\end{tabular}

Table (4) Shows that there are no statistical relationships between educational level and knowledge about hormone replacement therapy.

Table (5): Relationship between Absent of Menstrual cycle for more than one year and knowledge score regarding HRT

\begin{tabular}{|l|l|l|l|l|}
\hline \multirow{2}{*}{ Knowledge Score } & \multicolumn{2}{|l|}{ Absent of Menstrual cycle for more than one year } & \multirow{2}{*}{ P } & Sig. \\
\cline { 2 - 3 } & No (menopause) & Yes (still menstruating) & & \\
\cline { 1 - 3 } $\begin{array}{l}\text { Knowledge score-hormone } \\
\text { replacement therapy (HRT) }\end{array}$ & & & \multirow{2}{*}{0.49} & NS \\
\hline Range & $(0$ to 80$)$ & $(0$ to 75) & & \\
\hline Mean & 31.2 & 29.6 & & \\
\hline SD & 24 & 21.6 & \\
\hline SE & 2.14 & 1.3 & & \\
\hline N & 125 & 275 & \\
\hline
\end{tabular}

Table (5) Shows that there are no statistical relationships between Absent of Menstrual cycle for more than one year and knowledge about hormone replacement therapy.

Table (6): Relationship between using of HRT and knowledge score regarding HRT

\begin{tabular}{|l|l|l|l|l|}
\hline & Using HRT & S & Sig \\
\cline { 2 - 3 } & No & yes & & \\
\hline $\begin{array}{l}\text { Knowledge score-hormone } \\
\text { replacement therapy (HRT) }\end{array}$ & & & \multirow{2}{*}{0.012} & S \\
\hline Range & $(0$ to 75$)$ & $(0$ to 80$)$ & & \\
\hline Mean & 29.5 & 41.3 & \\
\hline
\end{tabular}




\begin{tabular}{|l|l|l|l|l|}
\hline SD & 22.2 & 21.7 & \multirow{3}{*}{} & \\
\cline { 1 - 3 } SE & 1.15 & 4.44 & & \\
\cline { 1 - 5 } & 374 & 24 & & \\
\hline
\end{tabular}

Table( 6) Shows there are statistical significant relationships between using HRT and knowledge regarding HRT.

\section{Discussion}

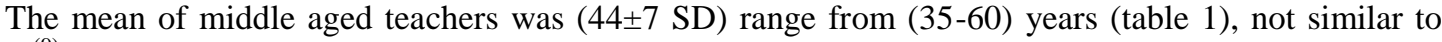
(Humaira) ${ }^{(9)}$ were the study conducted on One hundred women who came to outpatient department of Jinnah Medical College Hospital Karachi as a patient or as an attendant were interviewed, Sociodemographic characteristics, knowledge and attitude towards menopause and HRT were collected through a structured pretested questionnaire. Were the mean age of respondents was $(55.1 \pm 10 \mathrm{SD})$ years (range $40-65$ years). married,

The majority of them $(80.5 \%)$ were married (table 1$)$, similar to (Syed) ${ }^{(10)}$ the majority of sample were

The majority of sample $(74.8 \%)$ were college graduate not similar to (Serena) ${ }^{(11)}$ Investigating women's knowledge, attitude and practice in relation to menopause and systemic hormone therapy (HT) through a sample survey of women aged (45-60) years from five Italian regions, A total of 969 women were selected from electoral rolls. 720 of them completed the interview, were the $11 \%$ of them college graduate.

The majority of them (75.5\%) not menopause and (24.6\%) were menopause, not similar to (Hamid S) (12) study was carried out among women of age 40 and above, to assess Women's knowledge, attitude and practice towards menopause and hormone replacement therapy: a facility based study in Al-Ain, United Arab Emirates, The participants were administered a questionnaire in Arabic and English, which included 33 items; socio-demographic variables, and questions related to knowledge, attitude and practices regarding menopause and HRT, were $51 \%$ had already experienced menopause, while (49\%) not menopause,

The majority of sample (93.5\%) were not using HRT, while (6.5\%) using HRT (table 1), not similar to (Hussein $)^{(13)}$ To determine knowledge of hormone therapy HT, cross-sectional study was conducted through a cluster sampling among 330 women 40-60 year old, in Yazd, Islamic Republic of Iran, were 2.1\% of women were current usage of HRT.

Table (2) shows the highest percentage $(53.8 \%)$ of study sample correctly answer regarding item (2.6) which refer to response to HRT differs from one woman to another, $43.5 \%$ correctly answer regarding item (2.1) which refer to: Preferably A periodic check for the breast and level of blood lipids and BMD before starting treatment, $43.0 \%$ correctly answer regarding item (2.1) which refer to: taking HRT without medical advice may cause endometrial cancer, $42.5 \%$ correctly answer regarding item (2.1) which refer to: Hormone Replacement Therapy (HRT) is considered the optimal treatment for menopausal symptoms, $41.5 \%$ correctly answer regarding item (2.1) which refer to: women need HRT after hysterectomy, 40.3\% correctly answer regarding item (2.1) which refer to: HRT is prescribed in small quantities to balance the natural physiology of the body .

The table (3) show mean score of knowledge (30.1) with 22.3 SD had poor level of knowledge regarding hormone replacement therapy. Not similar to (P. Kavitha) ${ }^{(14)}$ study was conducted to assess the knowledge regarding hormone replacement therapy among menopausal women, Non-Experimental design, Purposive sampling technique was used to select 30 samples for the study, The tool used for the study was structured interview schedule, The data gathered were analyzed by using descriptive statistic, were the major findings of the study were showed that $46.7 \%$ of menopausal women had moderately adequate knowledge, $43.3 \%$ of menopausal women had inadequate knowledge, regarding Hormonal Replacement Therapy. (G. (A. Jassim,) ${ }^{(15)}$ study of Knowledge of Bahraini women about the menopause and hormone therapy: implications for health-care policy, aged 30-64 years, revealed that the knowledge of Bahraini women about menopause and HT is average. (Susan) ${ }^{(16)}$ Study was conducted to assess Knowledge of Menopause and Hormone Replacement Therapy Use in Low-Income Urban Women, A descriptive cross-sectional survey of 215 women , demographic characteristics, hormone therapy use, and knowledge about menopause and HRT were collected through a structured interview, the results revealed a general lack of knowledge about HRT. Not similar to (Saima) ${ }^{(17)}$ A clinic-based cross-sectional study was conducted among women of age 40 and above. Study subjects were recruited from four Primary Health Care centers in Al Ain city. The participants were administered a questionnaire in Arabic and English, which included 33 items; socio-demographic variables, and questions related to knowledge, attitude and practices regarding menopause and hormone replacement therapy were the result revealed that the women with high educational level (university) had good knowledge.

Table (4) Shows that there are no statistical relationships between educational level and knowledge about hormone replacement therapy. Not similar to (po) ${ }^{(18)}$ study was conducted To evaluate the use of hormone replacement therapy (HRT), the prevalence of climacteric symptoms, and the knowledge about HRT, a prospective study was conducted by telephone interview among a randomly selected population-based sample 
of 978 Hong Kong Chinese women aged (40-60) years, were the results show women with higher education level had better knowledge about HRT.

Table (5) Shows there are statistical significant relationships between using HRT and knowledge regarding HRT, Supported by (Eugenia) ${ }^{(19)}$ which revealed that The menopausal hormone therapy (MHT) group consisted of 100 women who were taking MHT and the non-MHT group consisted of 116 women who were not. By comparing the two groups, it became apparent that the MHT group of women were more likely to have higher knowledge $(\mathrm{p}<0.001)$ than other.

\section{Conclusion}

The study indicated that there is poor knowledge about HRT among the participants. Level of knowledge was not associated with level of education, while using hormone therapy significant relationship with knowledge score

\section{Recommendation}

1. More and qualified information should be provided to support women in making informed choices in relation to hormone replacement therapy.

2. Health education concerning hormone replacement therapy and its benefits and risks.

3. Further studies concerning hormone therapy and women health should be conducted

\section{References}

[1] Avrum Z. Bluming, MD, and Carol Tavris, PhD, Hormone Replacement Therapy: Real Concerns and False Alarms, The Cancer Journal, April 2009, Volume 15(2), PP: 93.

[2] Polly Dane Fraga; Christopher Vojta, , and Colleen Veloski, Review of Hormone Replacement Therapy for Disease Prevention, Inc., Sep 2000, vol 6(7), pp: 17

[3] Janet L. Stanford ; Patricia Hartge , Louise A. Brinton , and et al, Effect of hormone replacement therapy on cardiovascular events in recently postmenopausal women: the $\boldsymbol{b m j}$, Jun 2012, vol 11(4), PP: 255.

[4] Stevenson JC; Type and route of estrogen administration, PubMed, Feb 2009, vol 12(1), PP: 86-90.

[5] Grodstein F, Manson JE, Colditz GA, Willett WC, Speizer FE, Stampfer MJ. A prospective, observational study of postmenopausal hormone therapy and primary prevention of cardiovascular disease. Ann Intern Med 2000; vol 5(2), PP: 133.

[6] Million Women Study Collaborators. Breast cancer and hormone-replacement therapy in the Million Women Study. PubMed Aug 2003; vol 362(6), PP:419.

[7] Lori Mosca, MD, PhD; Peter Collins, MD; David M. Herrington, MD; and et al , Hormone Replacement Therapy and Cardiovascular Disease, circulation, 2001, vol 104, PP:499.

[8] Hemminki E. Hormone replacement therapy: discrepancies between evidence and recommendations. Scand J Public Health 2000; vol 28, PP:81-3

[9] Humaira Saeed Malik, Knowledge and attitude towards menopause and Hormone Replacement Therapy (HRT) among menopausal women, IPMA, April 2008, Vol. 58(4),PP: 164

[10] Syed alwi syed abdul rah, Z Siti Rubiah, Ping Yein Lee, and et al, Experience of hormone replacement therapy among women of Sarawak, Malaysia, research gate, Dec 2009, vol 13(6), PP:553.

[11] Serena Donati, Rodolfo Cotichini, Paola Mosconi, and et al, Menopause: Knowledge, attitude and practice among Italian women, Maturitas, July 2009, Volume 63(3), PP: 246-52

[12] Hamid S, Al-Ghufli FR, Raeesi HA, Al-Dliufairi KM, and et al, Women's knowledge, attitude and practice towards menopause and hormone replacement therapy: a facility based study in Al-Ain, United Arab Emirates, J Ayub Med Coll Abbottabad, Dec 2014, vol 26(4), PP:448.

[13] Hussein Fallahzadeh, Ph.D; Maryam Hossienzadeh, Ph.D., Fatemeh Yazdani, Ph.D., and Atefeh Javadi, Knowledge of reproductive physiology and hormone therapy in 40-60 year old women: a population-based study in Yazd, Iran, Iran J Reprod Med. IJRM , July 2012,vol 10(4), PP: 383.

[14] P. Kavitha, R. Aroun Prasath,and P. Krishnaraj, A study to assess the knowledge regarding hormonal replacement therapy among menopausal wmonen, International Journal of Preclinical and Pharmaceutical Research, 2012 , Vol 3(1), PP: 1-2.

[15] Dr G. A. Jassim and Q. M. Al-Shboul' Knowledge of Bahraini women about the menopause and hormone therapy: implications for health-care policy, tandfonline.July 2009,vol 12(1), PP: 38-48

[16] Susan E. Appling, Jerilyn K. Allen, Shirley Van Zandt, and et al, Knowledge of Menopause and Hormone Replacement Therapy Use in Low-Income Urban Women, Journal of Women's Health \& Gender-Based Medicine, July 2004, vol 9(1), PP:160

[17] Saima Hamid, Fatma Rashid Al-Ghufli*, Hanan Ali Raeesi, and et al, Women's Knowledge, Attitude and practice toward menopause and hormone replacement therapy, J Ayub Med Coll Abbottabad, 2014; vol 26(4), PP: 452.

[18] Po Mui Lam, Tse Ngong Leung Christopher Haines and et al, Climacteric symptoms and knowledge about hormone replacement therapy among Hong Kong Chinese women aged 40-60 years, MATURITAS, June 2003, vol 45(2), PP:99

[19] Eugenia D. Vlachou1, Elena Theodosopoulou2, Anna Kavga-Paltoglou3, Georgia Fasoi-Barka4, John Kalemikerakis3, and et at, Sociodemographic Characteristics and Quality-of-life of Greek Menopausal Women treated with Hormone Therapy, HEALTH SCIENCE JOURNAL 2014, VOL 8(3), PP: 318. 